\title{
EFICIÊNCIA AGRONÔMICA DA CULTURA DO TRIGO SUBMETIDA A DOSES DE NITROGÊNIO EM DIFERENTES ESTÁDIOS ONTOGÊNICOS
}

\author{
Diego Mattuella', Sergio Pedro Simioni ${ }^{1}$, Cristiane Segatto ${ }^{2}$, Camila Cigel $^{3}$, Cristiane Rosa Adams ${ }^{3}$, \\ Claudia Klein ${ }^{4}$, Cristiano Reschke Lajús ${ }^{4}$, André Sordi ${ }^{4}$
}

\author{
${ }^{1}$ Graduando em Agronomia, Universidade do Oeste de Santa Catarina (UNOESC). Rua Getúlio Vargas, 2125 - Bairro Flor da Serra - \\ Joaçaba - SC - CEP 89600-0002 \\ ${ }^{2}$ Doutoranda em Produção Vegetal Universidade do Estado de Santa Catarina - (UDESC) - Centro de Ciências Agroveterinárias (CAV). \\ Av. Luiz de Camões, 2090- Conta Dinheiro- Lages-SC- CEP 88.520-000 \\ ${ }^{3}$ Mestranda em Produção Vegetal Universidade do Estado de Santa Catarina - (UDESC)- Centro de Ciências Agroveterinárias (CAV). \\ Av. Luiz de Camões, 2090- Conta Dinheiro- Lages-SC- CEP 88.520-000 \\ ${ }^{4}$ Professor Dr do curso de Agronomia, Universidade do Oeste de Santa Catarina- (UNOESC) Rua Getúlio Vargas, 2125 - Bairro Flor da \\ Serra -Joaçaba - SC - CEP 89600-000 \\ Autor para correspondência: Cristiane Segatto, segattobio@gmail.com
}

RESUMO: O trigo é uma cultura amplamente cultivada, com importância na alimentação humana e na rotação de culturas, sendo cultivado no inverno requerendo adubação equilibrada conforme a demanda da cultura. 0 nitrogênio é um nutriente essencial para o desenvolvimento da cultura. 0 momento da aplicação é um fator fundamental para o bom aproveitamento do mesmo. Dessa forma, o presente trabalho teve por objetivo avaliar a eficiência agronômica e econômica da cultura do trigo submetida a doses de nitrogênio em diferentes estádios ontogênicos. 0 experimento foi conduzido no delineamento em blocos casualizados, em esquema de parcela subdividida (3x6), com três repetições, composto de 18 tratamentos, sendo estes alocados em parcela principal: estádios ontogênicos: perfilhamento, alongamento do colmo e parcelamento de $50 \% \mathrm{~N}$ no perfilhamento e $50 \%$ do $\mathrm{N}$ no alongamento. Na subparcela as respectivas doses assim distribuídas: $140 \%, 120 \%$, dose recomendada, 80 e $60 \%$, e uma testemunha (sem $\mathrm{N}$ em cobertura). As variáveis analisadas foram valores de SPAD, número de espiguetas, rendimento agronômico e econômico. Nas parcelas em que se elevou a dose de $\mathrm{N} \mathrm{em} 120 \%$ e $140 \%$, tanto em única aplicação ou parcelada, os resultados de rendimento e máxima eficiência técnica foram satisfatórios e as doses de 100\%, 120\% e 140\% apresentaram melhores resultados econômicos e oferecem melhor rentabilidade. A ferramenta SPAD comprovou que doses 120 e $140 \%$ de nitrogênio estão relacionadas um incremento de 15,5 e 46,5 \% respectivamente no rendimento de grãos. Os resultados econômicos, a dose com $140 \%$ de nitrogênio teve resultado financeiro maior. Recomenda-se dividir a dose de nitrogênio em duas aplicações, nos estádios perfilhamento e alongamento do colmo.

PALAVRAS CHAVE: Triticum aestivum. Doses de Nitrogênio. Rendimento. Eficiência Agro-financeira.

\section{AGRONOMIC EFFICIENCY OF WHEAT SUBMITTED TO NITROGEN DOSES AT DIFFERENT ONTOGENIC STAGES.}

ABSTRACT: Wheat is a widely cultivated crop, with importance in human food and crop rotation, being cultivated in winter requiring balanced fertilization according to the crop demand. Nitrogen is an essential nutrient for the development of the crop. The moment of the application is a fundamental factor for the good use of it. Thus, the present work had the objective of evaluating the agronomic and economic efficiency of the wheat crop submitted to nitrogen doses in different ontogenic stages. The experiment was carried out in a randomized complete block design (3x6), with three replications, consisting of 18 treatments, which were allocated to the main plot: ontogenic stages, being tillering, stem elongation and $50 \% \mathrm{~N}$ in the tillering and $50 \%$ of the $\mathrm{N}$ in the elongation. In the subplot the respective doses thus distributed: $140 \%, 120 \%$, recommended dose, 80 and $60 \%$, and one control (without $\mathrm{N}$ in coverage). The variables analyzed were SPAD, spikelet number, agronomic and economic yield. In the plots where the $\mathrm{N}$ dose was increased by $120 \%$ and $140 \%$, both in single application or in installments, the results of yield 
and maximum technical efficiency were satisfactory at a levels of $100 \%, 120 \%$ and $140 \%$ presented better economic results and offer better profitability. The SPAD tool proved that 120 and $140 \%$ nitrogen doses are related to an increase of 15.5 and $46.5 \%$, respectively, in grain yield. The economic results, the $140 \%$ nitrogen dose had a higher financial result. It is recommended to divide the nitrogen dose in two applications, at the tillering and stem elongation stages.

KEYWORDS: Triticum aestivum. Nitrogen levels. Yield. Agro-Economic efficiency.

\section{INTRODUÇÃO}

Com o aumento crescente da população mundial torna-se visível a grande demanda pela produção de alimentos, sendo o trigo matéria prima essencial para diversos setores da cadeia alimentícia. Com isso o triticultor tem como missão produzir matéria prima com qualidade e competitividade aliando a eficiência técnica produtiva à eficiência econômica. 0 incremento da produção desta cultura tem sido obtido através do uso de cultivares modernas em conjunto com o uso integrado e racional de recursos e a adoção de eficientes técnicas de manejo (Stefen et al., 2014).

$O$ nitrogênio $(N)$ é um dos nutrientes mais exigidos pela cultura e também o que apresenta maior efeito sobre a qualidade do grão (Teixeira Filho et al., 2010). De acordo com Pagliosa et al. (2013), a utilização de altas doses de adubação nitrogenada tem se tornado uma prática rotineira na busca da maximização da produção, aumento da qualidade do grão e melhoria da eficiência produtiva da espécie. No entanto, a aplicação de elevadas doses de nitrogênio pode acarretar em acamamento das plantas, prejudicando sua produtividade, qualidade e dificultando a colheita mecanizada de grãos (Zagonel e Fernandes, 2007).

Com o avanço das técnicas de cultivo surgiram insumos de alta tecnologia que visam fornecer à cultura do trigo condições nutricionais que se aproximem do ideal, a fim de que esta cultura possa manifestar o seu máximo potencial produtivo. Tendo em vista o custo elevado da adubação nitrogenada, tal prática deve ser racionalizada, pois elevará o custo e poderá tornar menos lucrativa esta atividade. É importante ressaltar que a indústria exige altos parâmetros de qualidade do trigo que são expressos no produto final. Plantas com condições nutricionais adequadas tendem a fornecer grãos com teores nutricionais mais elevados e adequados ao mercado consumidor.

Levando em consideração que a maioria dos triticultores sabe da importância da adubação nitrogenada de cobertura para obtenção de altos índices produtivos, surge a questão da quantidade adequada a ser aplicada e o exato momento desta aplicação sobre a cultura. Pois, doses abaixo da exigida pela cultura reduzirá o potencial de produção, e em doses superestimadas ocorrerá uma redução nos lucros do agricultor pelo gasto desnecessário em adubação nitrogenada, prejuízos ao ambiente, contaminação das águas superficiais e subterrâneas ocasionadas pela lixiviação do nitrato (Lajús et al., 2011).

Visando o uso eficiente do nitrogênio, a adoção de metodologias de baixo custo, rápidas e não destrutivas, como o teor de clorofila na folha via clorofilômetro, pode tornar-se uma ferramenta importante para aumentar a precisão no processo de recomendação de adubação nitrogenada para a cultura do trigo (Argenta et al., 2001). Os níveis de clorofila na folha são proporcionais à quantidade de nitrogênio absorvida pela planta (Booij et al., 2000). Assim, utilizar instrumentos para medir o teor de clorofila, é uma forma indireta de medir a absorção de nitrogênio e de verificar o equilíbrio nutricional da planta. 0 conteúdo de clorofila está correlacionado com a concentração de $\mathrm{N}$ na planta porque o $\mathrm{N}$ é necessário para a síntese de clorofila e quando em teores baixos de clorofila a planta não vai utilizar eficientemente a luz do sol para o processo fotossintético e consequente absorção de nutrientes (Reis et al., 2006).

Para se obter um melhor aproveitamento, e consequentemente uma maior produtividade de grãos, recomenda-se o parcelamento da aplicação do N, ou seja, de 15 a $20 \mathrm{~kg} / \mathrm{ha}$ na semeadura e o restante em cobertura no perfilhamento ou alongamento (CQFS-RS/ SC, 2004). Ajustes precisos nas doses de nitrogênio, na densidade de plantas conforme cada cultivar e época de semeadura são fatores importantes para se atingir 0 potencial produtivo pretendido em uma lavoura, porém pode resultar no acamamento da cultura, se aplicado em quantidades não recomendadas ou em épocas ontogênicas equivocadas, o que pode interferir na produção e na qualidade dos grãos.

Desta forma, objetivou-se neste trabalho avaliar a eficiência agronômica e econômica com 0 auxílio do medidor portátil de clorofila na cultura do trigo 
submetida a doses de nitrogênio aplicado em diferentes estádios ontogênicos.

\section{MATERIAL E MÉTODOS}

0 experimento foi conduzido entre os meses de maio a outubro de 2014, na área experimental da Universidade do Oeste de Santa Catarina - UNOESC Campus de São José do Cedro/SC, a 727 metros de altitude e coordenadas $26^{\circ} 28^{\prime} 40^{\prime \prime} S$ e $53^{\circ} 30^{\prime} 39^{\prime \prime}$ O (Google Earth, 2014). O clima da região é do tipo Cfa na classificação de Köeppen (Wrege et al., 2011), isto é, subtropical com chuvas bem distribuídas no verão, com temperatura superior a $22^{\circ} \mathrm{C}$. A temperatura média anual é em torno de $17^{\circ} \mathrm{C}$, podendo no verão atingir os $38^{\circ} \mathrm{C}$ e no inverno ter ocorrência de geadas. A precipitação média é de 1800 a 2000 milímetros por ano. $O$ solo onde foi conduzido o experimento é classificado como CAMBISSOLO HÁPLICO (Embrapa, 2013). Para as condições meteorológicas temperatura máxima, média, mínima e UR os dados utilizados foram obtidos com auxílio de um termohigrógrafo instalado a $1,50 \mathrm{~m}$ de altura, próximo da área onde o experimento foi conduzido, já os dados de precipitação foram obtidos com o auxílio de um pluviômetro devidamente instalado na mesma área.

0 delineamento experimental constitui de um DBC (delineamento em blocos casualizados) em esquema de parcela subdividida $(3 \times 6)$, com três repetições. Na parcela principal: estádios ontogênicos (3 níveis) compostos por três estratégias de aplicação de nitrogênio em cobertura, sendo a aplicação do nitrogênio no perfilhamento, no alongamento do colmo e a terceira pelo parcelamento da quantidade em $50 \%$ do $\mathrm{N}$ no perfilhamento e $50 \%$ do $\mathrm{N}$ no alongamento do colmo das plantas. Na subparcela foram alocadas as doses de $\mathrm{N}$ (6 níveis), que consistiram de 0,60, 80100 120 e $140 \%$ da dose recomendada de $\mathrm{N}\left(80 \mathrm{~kg}^{\mathrm{h}} \mathrm{ha}^{-1}\right)$ seguindo a recomendação da CQFS (2004) conforme análise de solo.

Cada unidade experimental foi constituída por uma área de $9 \mathrm{~m}^{2}(3 \times 3)$ e nesta uma área útil de $1 \mathrm{~m}^{2}$ ao centro da mesma. Foi respeitado um corredor entre cada parcela de 0,5m e uma área periférica de $3 \mathrm{~m}$ com objetivo de evitar possíveis interferências.

A adubação seguiu a recomendação da Comissão de Química e Fertilidade do Solo - RS/SC (CQFS-RS/ SC, 2004) e foram realizadas para um rendimento potencial de 6 t.ha-1 de grãos. A cultura antecessora a semeadura do trigo na área foi o milho (Zea mays). A dessecação foi realizada com 30 dias de antecedência da semeadura, com a utilização de pulverização mecanizada, na dose de três litros de Glifosato por hectare, totalizando $1440 \mathrm{~g}$ e. a.ha- ${ }^{-1}$. A semeadura do trigo, cultivar Ametista foi realizada na segunda quinzena do mês de maio (22/05/2014), pela sua indicação no zoneamento agroclimático. 0 espaçamento utilizado foi de $18 \mathrm{~cm}$ entrelinhas e uma profundidade de semeadura de $5 \mathrm{~cm}$. Foram utilizadas 75 sementes por metro linear totalizando $125 \mathrm{Kg}$ de sementes por hectare.

$O$ índice de clorofila foi estimado por meio do aparelho CLOROPHYLL METER - 502 denominado clorofilômetro SPAD (Soil-Plant Analysis Development Section, Minolta). Para que as coletas pudessem expressar confiabilidade, após a demarcação das parcelas, utilizou-se um quadrado devidamente confeccionado para esta finalidade, e com este, já colocado no centro da área útil, de cada parcela, marcou-se uma planta em cada canto e mais uma no centro da parcela. As leituras foram realizadas todas na mesma planta, e nesta em três posições da mesma folha: base, meio e final do limbo foliar e em três estádios de desenvolvimento: perfilhamento (20), alongamento de colmo (30) e bainha da folha bandeira totalmente expandida (37) conforme a escala de Zadoks et al. (1974).

Para a análise do número de espiguetas por planta foram coletadas aleatoriamente 10 plantas de cada parcela útil e realizado a contagem das mesmas, a partir dessa contagem obteve-se a média de espiguetas por planta.

As plantas da área útil foram colhidas em 29/10/2014, e após a colheita estas foram trilhadas, os grãos separados das impurezas, e então submetidos à determinação da umidade. Após estes procedimentos foram realizados os cálculos para estimar a produtividade de grãos em kg ha-1 $\mathrm{e}$ em sacas ha-1.

0 preço do $\mathrm{kg}$ do fertilizante foi obtido em pesquisa (Index Mundi, 2014), ficando R\$ 0,66 kg-1. Para o preço do trigo foi obtido com a cotação do mês de novembro de 2014, em pesquisa na Cepa Epagri (2014) em $R \$ 0,53 \mathrm{~kg}^{-1}$.

A determinação do peso de 1000 grãos (PMG) foi realizada de oito subamostras de 100 grãos, com posterior pesagem dos mesmos em balança eletrônica 
com precisão de $0,001 \mathrm{~g}$ e assim pelo valor médio obteve-se o PMG.

A avaliação da qualidade do trigo foi realizada através de seu $\mathrm{PH}$ (Peso hectolítrico, $\mathrm{kg} \mathrm{hL}^{-1}$ ), obtido em balança de $0,25 \mathrm{~L}$, e posteriormente convertida em $\mathrm{kg} 100$ $\mathrm{L}^{-1}$. Esta avaliação ainda é um critério de determinação do preço do grão do trigo ao agricultor que mede a relação entre o peso de seu endosperma, mais denso, e o volume ocupado pela amostra de grãos, e quanto maior o seu valor, maior será a quantidade de endosperma e menor será a quantidade de casca no grão.

A eficiência econômica foi baseada no método descrito em Minetto (2001), usando o termo margem bruta para quantificar a diferença entre receita bruta obtida e dispêndio efetuado em cada nível de manejo, pois no total do dispêndio não foram consideradas remunerações à terra, às instalações e às construções, nem juros sobre o desembolso.

A eficiência agronômica de uso do nitrogênio foi determinada pela quantidade de grãos colhidos na parcela (RG), dividido pela quantidade de $\mathrm{N}$ aplicado, resulta na eficiência agronômica de uso do $\mathrm{N}(\mathrm{kg} . \mathrm{kg}$ 1) que reflete 0 incremento de produção obtido por quilograma de $\mathrm{N}$ (Fageria et al., 2004).

Os dados coletados foram submetidos à análise de variância pelo teste $F(p \leq 0,05)$, quando houve diferença significativa as médias foram comparadas por teste Tukey a $5 \%$ de probabilidade (para o fator estratégia)e, para o fator doses por ajuste de regressão.

\section{RESULTADOS E DISCUSSÃO}

Os dados climáticos da região no período de condução do experimento são apresentados na Figura 1. As condições climáticas para o cultivo do trigo nem sempre foram favoráveis, pois, ocorreram chuvas intensas na colheita, causando a germinação dos grãos ainda na espiga (germinação pré-colheita). A temperatura, precipitação pluvial e a radiação solar são os de maior impacto, tanto no crescimento, quanto no desenvolvimento, na adaptação e na qualidade do trigo (Miralles e Slafer, 2000). Segundo Rodrigues et al. (1998), a deficiência hídrica no estágio de antese reduz $15 \%$ da massa e, quando há déficit no estágio de folha bandeira, esta redução chega a 19\%.

Visualiza-se que no mês de agosto ocorreram condições desfavoráveis para um bom perfilhamento $e$ emborrachamento da cultura do trigo com precipitação de $55 \mathrm{~mm}$. Já no mês de setembro de 2014, período em que coincide com a floração e frutificação, ocorreu um excesso de precipitação, $562 \mathrm{~mm}$. No mês de outubro, foi de $123 \mathrm{~mm}$, período de maturação fisiológica e consequente colheita (Figura 1).

Figura 1. Média de precipitação, temperatura e umidade relativa durante os meses de maio a setembro de 2014 , no município de São José do Cedro.

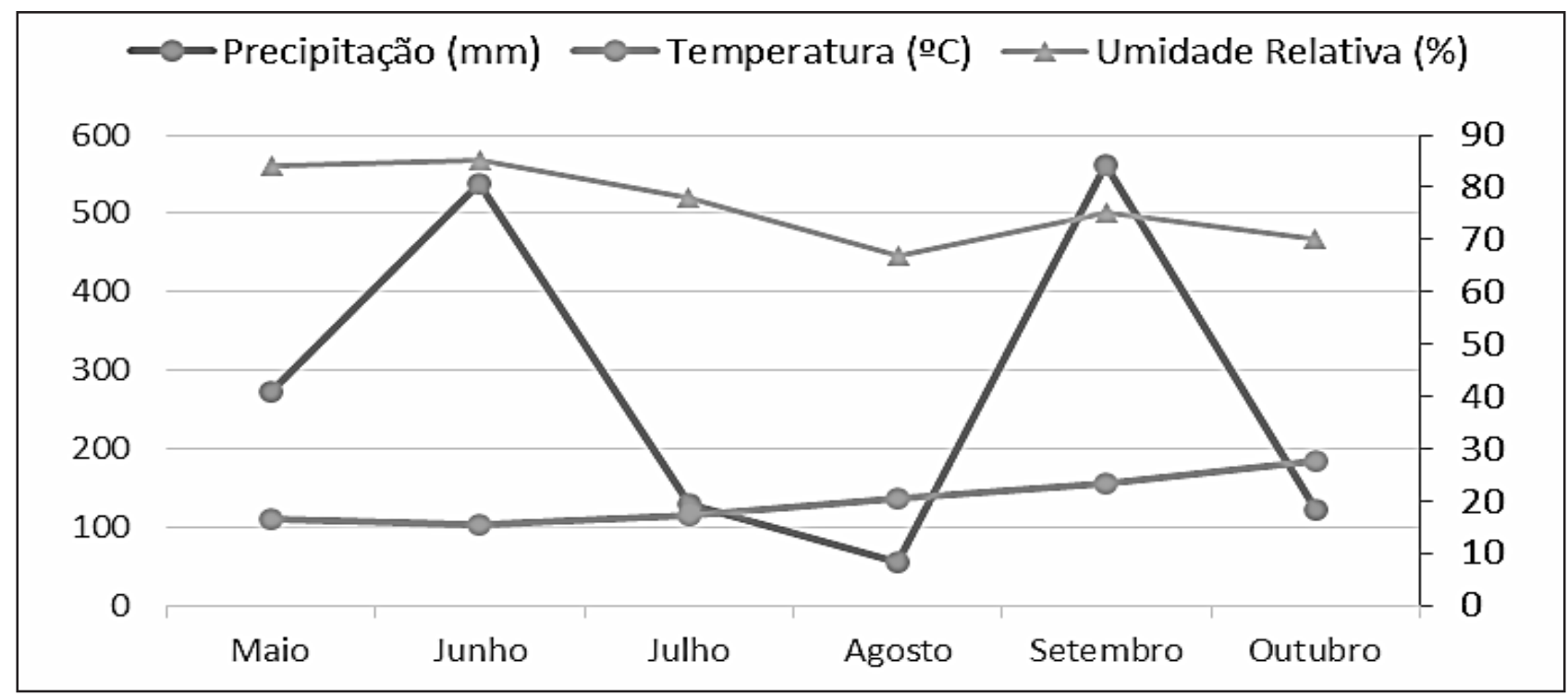

De acordo com as informações de Lajús et al. (2011), a precipitação ideal para o cultivo do trigo varia entre 450 a $550 \mathrm{~mm}$. Mas, durante todo o ciclo, ocorreram $1680 \mathrm{~mm}$ de precipitação, considerados acima da necessidade da cultura, e de forma desuniforme em relação à exigência durante 0 desenvolvimento vegetativo. Pois, nos meses de agosto e setembro, a quantidade de chuva foi considerada insuficiente $e$ 
pode ter influenciado negativamente o processo de perfilhamento e alongamento do colmo das plantas. Tal fato pode ser explicado pelo fenômeno El Niño, caracterizado na região Sul do País por um inverno mais curto de temperaturas mais elevadas, primavera chuvosa e pouco ensolarada (Floss, 2013).

Os resultados para a variável SPAD estão apresentados na Tabela 1. Os estádios ontogênicos e recomendações revelaram efeito significativo, sendo que para o fator estádios ontogênicos, aplicações de $\mathrm{N}$ no perfilhamento e parcelamento (perfilhamento + alongamento) diferiram significativamente da adubação nitrogenada no alongamento. Para o fator quantidade de nitrogênio, as maiores doses (96 e 112 kg.ha-1 de N, respectivamente, $120 \%$ e $140 \%$ da dose recomendada) diferiram significativamente da testemunha. Para a variável SPAD, avaliado na folha bandeira, apenas o fator recomendações de nitrogênio revelou efeito significativo. Isto é explicável, pois o parcelamento da adubação nitrogenada resulta em maior recuperação do nutriente pela cultura e maior produtividade, quando comparados com a aplicação única (Sangoi et al., 2007).

Tabela 1. Valores de SPAD nos estádios de perfilhamento (PERF), alongamento (ALON), parcelado e na folha bandeira (FB) na cultura do trigo (Triticum aestivumL.) submetida a diferentes estádios ontogênicos e recomendações de nitrogênio.

\begin{tabular}{|c|c|c|c|}
\hline Estádios de aplicação de N & SPAD - PERF & SPAD - ALON & SPAD - FB \\
\hline PERF & $45,61 \mathrm{a}$ & $47,14 \mathrm{a}$ & $46,25 a$ \\
\hline ALON & $40,81 \mathrm{~b}$ & $40,64 \mathrm{~b}$ & $45,35 \mathrm{a}$ \\
\hline PARC & $45,38 \mathrm{a}$ & $46,71 \mathrm{a}$ & $47,04 \mathrm{a}$ \\
\hline CV $(\%)$ & 5,68 & 2,88 & 5,16 \\
\hline \multicolumn{4}{|l|}{ Doses N (\%) } \\
\hline 0 & $40,56 \mathrm{~b}$ & $40,06 \mathrm{~b}$ & $39,38 b$ \\
\hline 60 & $43,30 \mathrm{ab}$ & $44,25 a b$ & $46,18 \mathrm{a}$ \\
\hline 80 & $44,27 \mathrm{ab}$ & $44,91 \mathrm{a}$ & $47,05 \mathrm{a}$ \\
\hline 100 & $44,44 \mathrm{ab}$ & $44,76 \mathrm{a}$ & $46,63 \mathrm{a}$ \\
\hline 120 & $45,45 a$ & $48,14 \mathrm{a}$ & $48,69 \mathrm{a}$ \\
\hline 140 & $45,56 \mathrm{a}$ & $46,88 \mathrm{a}$ & $49,33 a$ \\
\hline CV $(\%)$ & 5,47 & 5,71 & 4,32 \\
\hline
\end{tabular}

Médias seguidas de mesma letra minúscula não diferem entre si pelo teste de Tukey $(p \leq 0,05)$.

Observa-se na Tabela 1 que com 120e 140\% da dose recomendada de nitrogênio aplicado na cultura, 0 índice de clorofila apresentou resultados superiores nas três fases da análise feita com o SPAD (perfilhamento, alongamento e folha bandeira), demonstrando que ao aumentar as doses de $\mathrm{N}$ consequentemente eleva-se a concentração deste e de clorofila na planta. Segundo Teixeira Filho et al. (2010) em estudo utilizando da leitura SPAD, também obtiveram uma correlação positiva entre os teores de $\mathrm{N}$ e de clorofila da folha, com influência de $83 \%$, demonstrando uma associação positiva do uso do SPAD para a determinação de teor de $\mathrm{N}$ foliar.

Para o período compreendido entre a fase de emergência das plântulas até à diferenciação do primórdio floral, a falta de $\mathrm{N}$ reduz o número de espigas por área, a formação de espiguetas por espiga e, por consequência também irá reduzir o PMG de trigo (Frank e Bauer, 1996).
0 índice relativo de clorofila na folha avaliado pelo medidor portátil evidencia-se, como um parâmetro indicador do nível de nitrogênio em cereais. Além da sua utilização no manejo de $\mathrm{N}$, a determinação do índice de clorofila apresenta outras possibilidades de uso como na integração das medidas de solo com as leituras SPAD, na utilização em modelos de simulação de crescimento ou monitoramento de mudanças no grau de esverdeamento da folha e na verificação do nível de $\mathrm{N}$ nas plantas através de sensoriamento remoto (Argenta et al., 2001)

Para o número de espiguetas por planta pode-se observar que a dose recomendada de $\mathrm{N}$ $(100 \%)$ e as doses de 120 e 140\%, apresentaram diferenças significativas em relação às demais. Quanto aos estádios, apenas a aplicação com a dose dividida evidenciou diferença significativa no estádio de perfilhamento ou de alongamento do colmo (Tabela 2). 
Tabela 2. Número de espiguetas por planta de trigo (Triticum aestivum L.) submetida a aplicação de diferentes doses de nitrogênio nos diferentes estádios ontogênicos, perfilhamento (PERF), alongamento (ALON) e parcelado (PARC).

\begin{tabular}{|c|c|c|c|c|c|c|}
\hline \multirow{2}{*}{$\frac{\text { Doses de N }(\%)}{0}$} & \multicolumn{2}{|c|}{ PERF } & \multicolumn{2}{|c|}{ ALON } & \multicolumn{2}{|c|}{ PARC } \\
\hline & 31,00 & $\mathrm{Da}$ & 28,67 & $\mathrm{Da}$ & 30,33 & $\mathrm{Ca}$ \\
\hline 60 & 35,00 & $\mathrm{CDa}$ & 31,00 & $\mathrm{BCDb}$ & 32,67 & Cab \\
\hline 80 & 33,33 & $\mathrm{CDa}$ & 30,33 & $\mathrm{CDa}$ & 31,67 & $\mathrm{Ca}$ \\
\hline 100 & 36,67 & BCab & 34,33 & $\mathrm{BCb}$ & 40,00 & $\mathrm{Ba}$ \\
\hline 120 & 40,67 & $\mathrm{ABa}$ & 35,33 & $\mathrm{ABb}$ & 44,22 & Aba \\
\hline 140 & 43,00 & $A a b$ & 39,67 & $\mathrm{Ab}$ & 46,67 & $\mathrm{Aa}$ \\
\hline
\end{tabular}

Médias seguidas de mesma letra minúscula na linha e maiúscula na coluna não diferem entre si pelo teste de Tukey $(p \leq 0,05)$.

As doses de $\mathrm{N}$ influenciaram positivamente número de espiguetas por espiga, pois se ajustaram a uma função linear crescente. De acordo com Bredemeier e Mundstock (2001), houve aumento no número de espiguetas e no número de grãos por espiga quando o $\mathrm{N}$ foi aplicado por ocasião da terceira folha. Pois, a melhor condição nutricional, resultante da maior disponibilidade de $\mathrm{N}$ para as plantas, no momento da diferenciação da gema vegetativa em reprodutiva, pode ser responsável pela diferença nos componentes do rendimento (Espindula et al., 2010).

Segundo Foloni et al. (2014), doses acima de $80 \mathrm{~kg} \mathrm{ha}^{-1}$ de ureia na semeadura interferiram negativamente na produtividade do trigo diminuindo a população de plantas, enquanto doses entre 0 a
$80 \mathrm{~kg} \mathrm{ha}^{-1}$ somente na cobertura promoveram maior rendimento, e com doses maiores de $120 \mathrm{~kg} \mathrm{ha}^{-1}$, entre aplicação em semeadura e cobertura, houve decréscimo no rendimento de grãos devido ao acamamento de plantas.

$\mathrm{Na}$ tabela 3 observa-se que a dose com a máxima eficiência técnica foi a de $140 \%$ da dose recomendada para a cultura do trigo, com 0 parcelamento da adubação nitrogenada nos estádios de perfilhamento $x$ alongamento. Este resultado indica a necessidade de mais estudos referentes às recomendações de adubação nitrogenada para 0 extremo Oeste de Santa Catarina, bem como, reavaliar a resposta a adubação nitrogenada de cobertura no trigo cv. Ametista.

Tabela 3. Rendimento de grãos (sacos ha-1) da cultura do trigo (Triticum aestivum L.) submetida aos diferentes estádios ontogênicos, perfilhamento (PERF), alongamento (ALONG) e parcelado (PARC) em função das doses de nitrogênio aplicadas em cobertura.

\begin{tabular}{|c|c|c|c|c|c|c|}
\hline \multirow{2}{*}{$\frac{\text { Doses (\%) }}{0}$} & \multicolumn{2}{|c|}{ PERF } & \multicolumn{2}{|c|}{ ALONG } & \multicolumn{2}{|c|}{ Parcelado } \\
\hline & 43,58 & $\mathrm{Da}$ & 43,00 & $\mathrm{Da}$ & 40,15 & $\mathrm{Da}$ \\
\hline 60 & 50,37 & $\mathrm{Ca}$ & 49,83 & $\mathrm{Ca}$ & 51,83 & $\mathrm{Ca}$ \\
\hline 80 & 52,07 & $\mathrm{Ca}$ & 51,72 & $\mathrm{BAa}$ & 53,05 & $\mathrm{Ca}$ \\
\hline 100 & 53,76 & $\mathrm{Ca}$ & 53,64 & $\mathrm{BCa}$ & 55,55 & $\mathrm{Ca}$ \\
\hline 120 & 63,24 & $\mathrm{Ba}$ & 56,53 & $A B b$ & 64,18 & $\mathrm{Ba}$ \\
\hline 140 & 70,25 & $A b$ & 60,07 & $A c$ & 76,39 & $\mathrm{Aa}$ \\
\hline
\end{tabular}

Médias seguidas de mesma letra minúscula na linha e maiúscula na coluna não diferem entre si pelo teste de Tukey $(p \leq 0,05)$.

Em relação ao rendimento econômico, observa-se na Tabela 4 que quando se elevam as doses de nitrogênio, automaticamente se eleva os custos da produção da cultura em análise, por outro lado pode-se avaliar que o lucro líquido também melhora na mesma proporção justifica este incremento no custo. Observa-se ainda que o parcelamento da adubação incrementa o valor, quando comparado com a aplicação no estádio de perfilhamento, e mais expressivo ainda quando comparado a aplicação somente no estádio de alongamento do colmo. 
Tabela 4. Rendimento econômico considerando a Receita Total (RT), Custo (C) e Lucro (L) e Eficiência Agronômica do nitrogênio da cultura do trigo quando submetida a doses de nitrogênio mineral aplicado em cobertura nos estádios ontogênicos de perfilhamento (PERF), alongamento (ALON) do colmo e parcelado (PARC) das plantas.

\begin{tabular}{|c|c|c|c|c|c|c|c|c|c|}
\hline \multicolumn{10}{|c|}{ Rendimento Econômico (R\$) } \\
\hline \multirow{2}{*}{ Doses (\%) } & \multicolumn{3}{|c|}{ PERF } & \multicolumn{3}{|c|}{ ALON } & \multicolumn{3}{|c|}{ PARC } \\
\hline & RT & CT & $\mathrm{L}$ & RT & $\mathrm{C}$ & $\mathrm{L}$ & RT & $\mathrm{C}$ & $\mathrm{L}$ \\
\hline 0 & 1.419 & 1.281 & 138 & 1.430 & 1.281 & 149 & 1.314 & 1.281 & 33 \\
\hline 60 & 1.654 & 1.418 & 236 & 1.669 & 1.418 & 251 & 1.742 & 1.418 & 324 \\
\hline 80 & 1.703 & 1.461 & 242 & 1.693 & 1.461 & 232 & 1.786 & 1.461 & 324 \\
\hline 100 & 1.764 & 1.510 & 254 & 1.756 & 1.510 & 246 & 1.861 & 1.510 & 350 \\
\hline 120 & 2.088 & 1.536 & 552 & 1.894 & 1.536 & 358 & 2.156 & 1.536 & 620 \\
\hline 140 & 2.315 & 1.603 & 712 & 1.965 & 1.603 & 362 & 2.552 & 1.603 & 948 \\
\hline \multicolumn{10}{|c|}{ Eficiência Agronômica } \\
\hline \multicolumn{2}{|c|}{ Doses (\%) } & \multicolumn{3}{|c|}{$\mathrm{kg} \mathrm{kg}^{-1}$} & \multicolumn{2}{|c|}{$\mathrm{kg} \mathrm{kg}^{-1}$} & & \multicolumn{2}{|c|}{$\mathrm{kg} \mathrm{kg}^{-1}$} \\
\hline \multicolumn{2}{|l|}{0} & \multicolumn{3}{|c|}{-} & \multicolumn{2}{|c|}{-} & & \multicolumn{2}{|c|}{-} \\
\hline \multicolumn{2}{|l|}{60} & \multicolumn{3}{|c|}{63,0} & \multicolumn{2}{|c|}{62,3} & & \multicolumn{2}{|c|}{64,8} \\
\hline \multicolumn{2}{|c|}{80} & \multicolumn{3}{|c|}{48,8} & \multicolumn{2}{|c|}{48,5} & & \multicolumn{2}{|c|}{49,7} \\
\hline \multicolumn{2}{|c|}{100} & \multicolumn{3}{|c|}{40,3} & \multicolumn{2}{|c|}{40,2} & & \multicolumn{2}{|c|}{41,7} \\
\hline \multicolumn{2}{|c|}{120} & \multicolumn{3}{|c|}{39,5} & \multicolumn{2}{|c|}{35,5} & & \multicolumn{2}{|c|}{40,1} \\
\hline \multicolumn{2}{|c|}{140} & \multicolumn{2}{|r|}{37,6} & & \multicolumn{2}{|c|}{32,2} & & \multicolumn{2}{|c|}{40,9} \\
\hline
\end{tabular}

Os fatores que podem interferir na formação dos preços agrícolas ramificam-se em distintos setores, passando por condições não controláveis, como por exemplo, condições climáticas, a até comportamentos econômicos de consumo interno e internacional. A produção agrícola se enquadra em uma estrutura de mercado atomizada, ao considerar um produtor individualmente, sua atividade, ou seja, a sua entrada ou saída do mercado não interferirá nos processos de formação de preços mundiais, além disso, o preço agrícola, devido a sua dependência de altas produtividades e qualidade, necessita de fatores climáticos que favoreçam essas características (Reis, 2007). Caracteriza-se, então uma produção sazonal, tanto temporal, devido condições climáticas, quanto geograficamente, conforme disponibilidade de fatores produtivos na região, capazes de tornarem seus preços reféns de uma oferta em determinadas épocas e áreas distintas.

Outro ponto a ser notado na formação de preço de um produto agrícola, é a sua alta perecibilidade, por também apresentar alto volume pós-colheita, 0 que exige um transporte e armazenamento em boas condições o que gera maior custo e consequentemente interferência em seus preços.

Analisando o estádio de perfilhamento, podese observar uma grande vantagem econômica entre a maior dose $(140 \%)$ com relação à dose interpretada e recomendada pela análise de solo segundo a CQFS (2004). O lucro obtido nesta dose foi muito superior à testemunha, apresentando viabilidade na aplicação nitrogenada. Observa-se ainda uma proximidade entre o custo de semeadura e a rentabilidade na testemunha. Por este fator pode-se inferir que a adubação nitrogenada não interfere muito no custo final do cultivo.

Analisando o estádio de alongamento, pode-se avaliar uma proximidade muito grande entre as doses. 0 lucro líquido obtido entre as doses mostra que ao aplicarse nitrogênio somente no estádio de alongamento, o mesmo não trará resultados satisfatórios para a cultura. Pois, nesta fase da cultura já se definiu seus fatores de rendimento (Frank e Bauer, 1996); e, portanto, não haverá posterior recuperação.

A adubação nitrogenada deve ser aplicada em duas épocas, na semeadura e em cobertura, sendo a cobertura realizada na fase de perfilhamento das plantas do trigo. A recomendação para o trigo no Paraná, quando a cultura anterior for soja, varia de 10 a $30 \mathrm{~kg} \mathrm{ha}^{-1}$ de $\mathrm{N}$ aplicado na semeadura e 30 a $60 \mathrm{~kg} \mathrm{ha}^{-1}$ de $\mathrm{N}$ aplicado em cobertura. Quando a cultura anterior for o milho, varia de 25 a $30 \mathrm{~kg} \mathrm{ha}^{-1}$ de $\mathrm{N}$ aplicado na semeadura e 30 a $90 \mathrm{~kg} \mathrm{ha}^{-1}$ de $\mathrm{N}$ aplicado em cobertura (Reunião da Comissão Brasileira de Pesquisa de Trigo E Triticale, 2012). Mas, as quantidades também variam em função do potencial produtivo planejado para a lavoura. 
Com relação a resultados econômicos, a dose com $140 \%$ de nitrogênio teve resultado financeiro maior com relação à testemunha nos três estádios analisados. No estádio de perfilhamento e alongamento, isso é explicado pelo fato de que o parcelamento da dose de nitrogênio, aplicado no momento correto e em condições climáticas adequadas, melhora o desempenho da cultura.

Quando analisado o resultado econômico (Tabela 4) pode-se observar que quando as doses de nitrogênio são parceladas nos estádios de perfilhamento e alongamento do colmo, elevando a dose para $140 \%$, obtém-se resultado econômico mais rentável para a cultura do trigo comparado a $100 \%$ do $\mathrm{N}$.

Segundo Bredemeier e Mundstock (2001), o nitrogênio deve ser disponibilizado às plantas de trigo preferencialmente entre a emergência e a emissão da sétima folha do colmo principal. No início deste período, há forte exigência de $\mathrm{N}$ para estabelecer 0 número de espiguetas diferenciadas e, em consequência, 0 número de grãos por espiga. Na época da emissão da sétima folha, o suprimento de nitrogênio é crítico para determinar o número de colmos que sobrevivem e produzem espigas, refletindo diretamente nos grãos a serem produzidos pelos perfilhos.

No que diz respeito à dose de nitrogênio, trabalhos relatam diferentes quantidades ótimas, 0 que é atribuído, principalmente, à cultura anterior, teor de matéria orgânica do solo, as condições climáticas, cultivar, dentre outros. Contudo, vale ressaltar que a melhor resposta para as cultivares estudadas foi obtida na dosagem de $60 \mathrm{~kg} \mathrm{ha}^{-1}$ de N. Na região sul do Paraná o maior rendimento de grãos foi obtido utilizando a dosagem de nitrogênio de $180 \mathrm{~kg} \mathrm{ha}^{-1}$; os autores utilizaram genótipos de elevado potencial produtivo, embora que, a partir de certas doses, variável de acordo com o genótipo, o incremento em produtividade não foi economicamente viável (PINNOW et al., 2009).

Desta forma, recomenda-se dividir altas doses de nitrogênio, correspondentes a 120 e 140\% (96 e $112 \mathrm{~kg}$ ha $^{-1}$ de N, respectivamente) em duas aplicações em cobertura, sobre plantas de trigo, nos estádios perfilhamento e alongamento do colmo. As doses de 120 e $140 \%$ apresentaram melhores resultados econômicos e oferecem melhor rentabilidade, embora sejam de menor eficiência agronômica do uso do N. A ferramenta SPAD obtida com o auxílio do clorofilômetro comprovou que doses 120 e 140\% de nitrogênio estão relacionadas com o melhor rendimento de grãos e retorno financeiro maior.

\section{REFERÊNCIAS BIBLIOGRÁFICAS}

Argenta, G.; Silva, P.R.F.; Bortolini, C.G. Clorofila na folha como indicador do nível de nitrogênio em cereais. Ciência Rural, 2001, 31, 4, 715- 722.

Booij, R.; Valenzuela, J.L.; Aguilera, C. Determination of crop nitrogen status using non-invasive methods. In: haverkort, A.J.; Mackerron, D.K.L. (Eds.). Management of nitrogen and water in potato production. Wageningen Pers, 2000, 72-82.

Bredemeier, C.; Mundstock, C. M. Estádios fenológicos do trigo para a adubação nitrogenada em cobertura. Revista Brasileira de Ciência do Solo, 2001, 25, 2, 317-323.

CEPA - Centro de Socioeconômica e Planejamento Agrícola. Mercado Agrícola: Preços agrícolas mensais. Disponível em: <http://docweb.epagri.sc.gov.br/ website_cepa/precos/preco_recebido_produtor.xls>. Acesso em: 01 de out. 2018.

CQFS - Recomendações de adubação e calagem para os estados do Rio Grande do Sul e Santa Catarina. 3.ed. Passo Fundo. SBCS- Núcleo Região Sul/ UFRGS, 2004; $400 p$.

Embrapa - Empresa Brasileira de Pesquisa Agropecuária -Solos. 2013. Disponível em: http:/l livraria.sct.embrapa.br/liv_resumos/pdf/00053080.pdf. Acesso em: 02 de dezembro de 2014.

Espindula, M.C.; Rocha, V.S.; De Souza, L.T.; De souza, M.A.; Grossi, J.A.S. Efeitos de reguladores de crescimento na elongação do colmo de trigo. Acta Scientiarum. Agronomy, 2010, 32, 1, 109-116.

Fageria, N.K.; Barbosa Filho, M.P.; Stone, L.F. Nutrição de fósforo na produção de feijoeiro. In: Yamada, T.; Abdalla, S.R.S. ed. Fósforo na agricultura Brasileira. Piracicaba: Associação Brasileira para Pesquisa da Potassa e Fosfato, 2004. 435 -455.

Frank, A.B.; Bauer, A. Temperature, nitrogen and carbon dioxide effects on spring wheat development and spikelet numbers. Crop Science, 1996, 36, 3, 659- 665. 
FLOSS, E.L. Fisiologia das plantas cultivadas. Brasil: Editora Universitária, Passo Fundo; 2011. 545p.

Foloni, J.S.S.; Bassoi, M.C.; Oliveira Junior, A.; Castro, C. Fontes e doses de nitrogênio na adubação de semeadura do trigo no Paraná. Londrina: Embrapa Soja. 34p. 2014.

Google Earth. Google Mapas de São José do CedroBrasil, 2014. Disponível em:<https://maps.google.com. br/maps>. Acesso em: 22 nov. 2014.

Index Mundi. Preços de mercadorias: Ureia vs Ureia Price Rate of Change Comparison. 2014. Disponivel em: <https://www.indexmundi.com/pt/pre\%C3\%A7osde-mercado/?mercadoria=ureia\&meses $=120 \&$ moeda $=$ brl\&mercadoria=ureia>. Acesso em 01 out. 2018.

Manfroi, E.; Lajús, C.R; Langhinotti, C.W.; Sonaglio, M.; Echer, G.; Parize, G.L.; Vanin, M.; Tambosi, M.C; Demartini, R.; Ranzan, T. Rendimento de trigo (Triticum aestivum L.) sob diferentes densidades de semeadura e doses de nitrogênio. In: III Seminário Integrado: Ensino, Pesquisa e Extensão, 2011, Chapecó. Ética e Ciência nas Diferentes Dimensões da Educação Superior, 2011.

Minetto, T.J. Custos de produção: lavouras em plantio direto. Porto Alegre: Fecoagro, 2001. 31p.

Miralles, D.J.; Slafer, G.A. Wheat development. In: Satorre, E.H.; Slafer, G.A. (Eds.). Wheat: ecology and physiology of yield determination. Food Products, 2000, 13-43.

Pagliosa, E.E.; Benin, G.; Biezus, E.; Beche, E.; Silva, C.L.; Marchese, J.A.; Martin, T.N. Trinexapac-ethyl e adubação nitrogenada na cultura do trigo. Planta Daninha, 2013, 31, 623-630.

Pinnow, C; Benin, G; Pagliosa, E. S; Signorini, A.A.; Lemes, C.; Beche, E.; Franke, J. Rendimento de diferentes genótipos de trigo em resposta a diferentes doses de nitrogênio. In: XIV Seminário de iniciação científica e tecnológica (sicite) 2009, pato branco. xiv seminário de iniciação científica e tecnológica (SICITE), Anais... 2009.

Reis, R.P. Fundamentos de economia aplicada. Lavras: UFLAIFAEPE, 95p. Curso de Especialização PósGraduação "Lato Sensu" (Especialização) a distância. 2007.
Reis, A.R.; Furlani, E.J.; Buzeti, S.; Andreotti, M. Diagnóstico da exigência do cafeeiro em nitrogênio pela utilização do medidor portátil de clorofila. Bragantia, 2006, 65, 1, 163-171.

Reunião da Comissão Brasileira de Pesquisa de Trigo e Triticale. 2013, Londrina, PR. Atas e resumos... Londrina: Comissão Brasileira de Pesquisa de Trigo e Triticale: Embrapa Trigo: 2012, 225p.

Rodrigues, O.; Lhamby, J.C.B.; Didonet, A.D.; Marchese, J.A.; scipioni, C. Efeito da deficiência hídrica na produção de trigo. Pesquisa Agropecuária Brasileira, $1998,33,6,839-846$.

Sangoi, L.; Berns, A.; Almeida, M.L.; Zanin, C.G.; Schweitzer, C. Características agronômicas de cultivares de trigo em resposta a época de adubação nitrogenada em cobertura. Ciência Rural, 2007, 37, 6, 1564-1570.

Stefen, D.L.V; Souza, C.A; Coelho, C.M.M.; Tormen M.E.; Zanesco, P.R.; Casa, R.T; Sangoi. L.; Nunes, F.R. Adubação nitrogenada associada ao emprego de reguladores de crescimento em trigo cv. Mirante. Revista de Ciências Agroveterinárias, 2014, 13, 1, 3039.

Teixeira Filho, M.C.M.; Buzetti, S.;Andreotti, M.;ARF, O.; Benett, C.G.S. Doses, fontes e épocas de aplicação de nitrogênio em trigo írrigado em plantio direto. Pesquisa Agropecuária Brasileira, 2010, 45, 8, 797-804.

Wrege, M.S.; Steinmetz, S.; Reisser, C.J.; Almeida, I.R. Atlas climático da Região Sul do Brasil: Estados do Paraná, Santa Catarina e Rio Grande do Sul. Embrapa Clima Temperado, Pelotas. Embrapa Florestas, Colombo, 2011. 336 p.

Zadoks, J.C.; Chang, T.T.; Konzak, C.F. A decimal code for the growth stages of cereals. Weed Research, 1974, $14,6,415-421$.

Zagonel, J.; Fernandes, E.C. Doses e épocas de aplicação de redutor de crescimento afetando cultivares de trigo em duas doses de nitrogênio. Planta Daninha, 2007, 25, 331-337. 